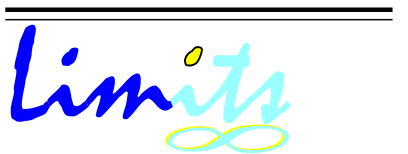

J. Math. and Its Appl.

ISSN : 1829-605X

Vol. 2, No. 1, May. 2005, 37-45

\title{
Ruang Barisan Orlicz Selisih Dengan Fungsional Aditif Dan Kontinunya
}

\author{
Sadjidon \\ Jurusan Matematika \\ Institut Teknologi Sepuluh Nopember, Surabaya
}

\begin{abstract}
Abstrak
Pada paper ini dibahas tipe lain ruang barisan Orlicz selisih, $\ell_{\varphi}(\Delta)$, yang didefinisikan sebagai: $\ell_{\varphi}(\Delta):=\left\{x=\left(x_{k}\right): \Delta x \in \ell_{\varphi}\right\}$ dengan $\Delta x=$ $\left(\Delta x_{k}\right)=\left(x_{k}-x_{k-1}\right)$. Selanjutnya, ruang yang dilengkapi dengan norma $\|x\|=\left|x_{1}\right|+\|\Delta x\|_{\ell_{\varphi}}$ merupakan ruang bernorma- $F$ yang lengkap dan juga mempunyai sifat $A K$. Berdasarkan pengertian fungsional aditif dan kontinu pada ruang barisan Orlicz, $\ell_{\varphi}$, dibahas fungsional aditif dan kontinu pada ruang barisan Orlicz selisih.
\end{abstract}

Kata kunci: Ruang bernorma-F yang lengkap, Sifat AK, Ruang barisan Orlicz selisih, Fungsional aditif dan kontinu

\section{Pendahuluan.}

Representasi fungsional aditif orthogonal pada beberapa ruang barisan telah banyak dibicarakan antara lain dalam [1]. Sedangkan untuk ruang barisan, khususnya ruang barisan Orlicz [3][4] telah membahasnya secara lengkap. Lebih lanjut [3] membahas fungsional aditif dan kontinu pada ruang barisan Orlicz. Sementara itu [2] memperkenalkan beberapa ruang barisan selisih antara lain $\ell_{\infty}(\Delta), c_{0}(\Delta)$. Berdasarkan [2] ini serta memperhatikan hasil-hasil penelitian dari [4] , maka dicoba mengkontruksi suatu ruang barisan selisih yang lain yaitu ruang barisan Orlicz 
sesilih. Disamping itu dengan memperhatikan hasil-hasil dari [2] dapat dikonstruksi pula fungsional aditif dan kontinu pada ruang barisan Orlicz selisih.

\section{Ruang Bernorma- $F$}

Diberikan $X$ ruang barisan bilangan real yang merupakan ruang vektor atas $R$. Jika $X$ dilengkapi dengan norma- $F$ yaitu norma $\|$.$\| yang memenuhi :$

(i) $\|x\| \geq 0 ;\|x\|=0 \Longleftrightarrow x=0$

(ii) $\|x\|=\|-x\|$

(iii) $\|x+y\| \leq\|x\|+\|y\|$ untuk semua $x, y \in X$

(iv) $\left\|\alpha_{n} x^{(n)}-\alpha x\right\| \rightarrow 0$ jika $\alpha_{n} \rightarrow \alpha$ dan $\left\|x^{(n)}-\alpha x\right\| \rightarrow 0$

maka $X$ disebut ruang barisan bernorma- $F$. Jika $X$ ruang barisan bernorma- $F$ yang lengkap, maka $X$ disebut ruang Frechet.

Selanjutnya, ruang Frechet $X$ dikatakan ruang $F K$ jika untuk setiap $k$, fungsi $P_{k}: X \rightarrow R$. dengan $P_{k}(x)=x_{k}$ kontinu.

Barisan blok $\left\{z^{n}\right\}$ di dalam ruang barisan $X$ adalah suatu barisan dengan elemen ke- $n$ yaitu :

$$
z^{n}=\left\{0, \cdots, 0, z_{i(n-1)+1}, \cdots, z_{i(n)}, 0, \cdots\right\}
$$

dengan $i(0)=0$ dan $\{i(n)\}$ adalah suatu barisan naik dari bilangan asli.

Misalkan $X$ suatu ruang barisan bernorma- $F$, maka $X$ dikatakan mempunyai Gliding Hump Property $(G H P)$, jika untuk setiap barisan blok $\left\{z^{n}\right\}$ dengan $\left\|z^{n}\right\| \rightarrow 0$ untuk $n \rightarrow \infty$, terdapat suatu barisan bagian bilangan asli $\{n(k)\}$ sehingga $\sum_{k=1}^{\infty} z^{n(k)} \in X$.

Mudah dipahami bahwa setiap ruang barisan bernorma- $F$ yang lengkap mempunyai $G H P$.

\section{Ruang Barisan Orlicz Selisih}

Diberikan $\varphi$ fungsi kontinu bernilai real naik pada $[0, \infty)$ dengan $\varphi(0)=0$ dan $\varphi(t)=\varphi(|t|)$ untuk semua $t$. Fungsi ini disebut fungsi Orlicz. Suatu himpunan Orlicz dinotasikan dengan $\ell_{\varphi}$ adalah himpunan semua $x=\left\{x_{k}\right\}$ sehingga

$$
\rho(x)=\sum_{k=1}^{\infty}<+\infty \quad \text { atau } \quad \ell_{\varphi}=\left\{x=\left\{x_{k}\right\} ; \sum_{k=1}^{\infty} \varphi\left(x_{k}\right)<+\infty\right\}
$$


Mudah ditunjukkan bahwa himpunan Orlicz $\ell_{\varphi}$ merupakan himpunan konvex. Suatu fungsi $\varphi$ dikatakan memenuhi kondisi $\delta_{2}$ jika terdapat $\alpha>0$ dan $\beta>0$ sehingga

$$
\varphi(2 t) \leq \alpha \varphi(t) \quad \text { untuk } \quad|t| \leq \beta
$$

Fungsi Orlicz $\varphi$ ternyata memenuhi kondisi $\delta_{2}$, sehingga himpunan Orlicz $\ell_{\varphi}$ merupakan ruang linier.

Selanjutnya, didefinisikan suatu norma pada $\ell_{\varphi}$ dengan:

$$
\|x\|=\inf \left\{\xi>0 ; \rho\left(\frac{x}{\xi}\right) \leq \xi\right\}
$$

untuk setiap $x \in \ell_{\varphi}$. Ruang $\ell_{\varphi}$ yang dilengkapi dengan norma di atas merupakan ruang bernorma- $F$ yang lengkap atau ruang Frechet dan disebut ruang barisan Orlicz.

Sekarang akan diberikan pengertian ruang barisan Orlicz selisih. Seperti halnya ruang barisan Orlicz, himpunan barisan Orlicz selisih didefinisikan sebagai: $\ell_{\varphi}(\Delta)=\left\{x=\left(x_{k}\right) ; \Delta x \in \ell_{\varphi}\right\}$ dengan $\Delta x=\left(\Delta x_{k}\right)=\left(x_{k}-x_{k-1}\right)$. Bahwa ruang $\ell_{\varphi}(\Delta)$ merupakan ruang linier.

Selanjutnya, didefinisikan suatu norma pada $\ell_{\varphi}(\Delta)$ dengan $\|x\|=\left|x_{1}\right|+$ $\|\Delta x\|_{\ell_{\varphi}}$. Dengan norma ini, akan ditunjukkan bahwa $\ell_{\varphi}(\Delta)$ merupakan ruang bernorma yang lengkap. Hal ini akan dijabarkan dalam teorema berikut.

Teorema 3.1 Ruang $\ell_{\varphi}(\Delta)$ merupakan ruang bernorma- $F$ dengan norma $\|x\|=$ $\left|x_{1}\right|+\|\Delta x\|_{\ell_{\varphi}}$.

Bukti. Diambil sebarang $x, y \in \ell_{\varphi}(\Delta)$

(i) Jelas bahwa $\|x\|=\left|x_{1}\right|+\|\Delta x\|_{\ell_{\varphi}} \geq 0$.

$$
\begin{aligned}
\|x\|=\left|x_{1}\right|+\|\Delta x\|_{\ell \varphi}=0 & \Longleftrightarrow\left|x_{1}\right|=0 \text { dan }\|\Delta x\|=0 \\
& \Longleftrightarrow x_{1}=0 \text { dan } \Delta x=x_{k}-x_{k-1}=0 \\
& \Longleftrightarrow x_{1}=\cdots=x_{k-1}=x_{k}=0, \text { untuk setiap } k \\
& \Longleftrightarrow x=\theta
\end{aligned}
$$

(ii)

$$
\begin{aligned}
\|-x\| & =|-x|+\|\Delta(-x)\|_{\ell_{\text {varphi }}} \\
& =|-x|+\|-\Delta x\|_{\ell_{\text {varphi }}} \\
& =|x|+\|\Delta x\|_{\ell_{\text {varphi }}} \\
& =\|x\|
\end{aligned}
$$


(iii) Akan ditunjukkan $\|x+y\|=\leq\|x\|+\|y\|$.

$$
\begin{aligned}
\|x+y\| & =\left|x_{1}+y_{1}\right|+\|\Delta x+\Delta y\|_{\ell_{\text {varphi }}} \\
& \leq\left|x_{1}\right|+\left|y_{1}\right|+\|\Delta x\|_{\ell_{\text {varphi }}}+\Delta y \|_{\ell_{\text {varphi }}} \\
& \leq\left|x_{1}\right|+\|\Delta x\|_{\ell_{\text {varphi }}}+\left|y_{1}\right|+\Delta y \|_{\ell_{\text {varphi }}} \\
& \leq\|x\|+\|y\|
\end{aligned}
$$

Dengan demikian $\|x+y\|=\leq\|x\|+\|y\|$.

(iv)

$$
\begin{aligned}
\left\|\alpha_{n} x^{(n)}-\alpha x\right\| & =\left\|\alpha_{n} x^{(n)}-\alpha_{n} x+\alpha_{n} x-\alpha x\right\| \\
& \leq\left\|\alpha_{n} x^{(n)}-\alpha_{n} x\right\|+\left\|\alpha_{n} x-\alpha x\right\| \\
& \leq\left|\alpha_{n}\right|\left\|x^{(n)}-x\right\|+\left|\alpha_{n}-\alpha\right|\|x\|
\end{aligned}
$$

Jika $\alpha_{n} \rightarrow \alpha$ dan $\left\|x^{(n)}-x\right\| \rightarrow 0$, maka $\left\|\alpha_{n} x^{(n)}-\alpha x\right\| \rightarrow 0$

Dengan demikian terbukti bahwa ruang barisan Orlicz selisih merupakan ruang bernorma- $F$.

Teorema 3.2 Ruang $\ell_{\varphi}(\Delta)$ yang dilengkapi dengan norma $\|x\|=x_{1} \mid+\|\Delta x\|_{\ell_{\varphi}}$ merupakan ruang bernorma-F yang lengkap atau ruang Frechet dan disebut ruang barisan Orlicz selisih.

Bukti. Tinggal membuktikan bahwa $\ell_{\varphi}(\Delta)$ adalah lengkap. Diberikan $\left\{x^{(n)}\right\}$ adalah barisan di $\ell_{\varphi}(\Delta)$ sedemikian hingga

$$
\left\|x^{(n)}-x^{(m)}\right\| \rightarrow 0, \quad \text { untuk } \quad n, m \rightarrow \infty
$$

Oleh karena itu

$\left\|x^{(n)}-x^{(m)}\right\|=\left|x_{1}^{(n)}-x_{1}^{(m)}\right|+\left\|\Delta x^{(n)}-\Delta x^{(m)}\right\|_{\ell_{\varphi}} \rightarrow 0, \quad$ untuk $\quad n, m \rightarrow \infty$

Dengan demikian diperoleh :

a. $\left|x_{1}^{(n)}-x_{1}^{(m)}\right| \rightarrow 0$, untuk $n, m \rightarrow \infty$

b. $\left\|\Delta x^{(n)}-\Delta x^{(m)}\right\|_{\ell_{\varphi}} \rightarrow 0$ untuk $n, m \rightarrow \infty$

atau $\left\|\left(x_{k}^{(n)}-x_{k-1}^{(n)}\right)-\left(x_{k}^{(m)}-x_{k-1}^{(n)}\right)\right\| \rightarrow 0$, untuk $n, m \rightarrow \infty$

atau $\left\|x_{k}^{(n)}-x_{k-1}^{(n)}\right\|_{\ell_{\varphi}} \rightarrow 0$ dan $\left\|x_{k}^{(m)}-x_{k-1}^{(n)}\right\|_{\ell_{\varphi}} \rightarrow 0$, untuk $n, m \rightarrow \infty$ 
Karena $\varphi$ kontinu dan naik pada $[0, \infty)$, maka untuk setiap $k$ diperoleh

$$
\left|x_{k}^{(n)}-x_{k}^{(m)}\right| \rightarrow 0, \quad \text { untuk } n, m \rightarrow \infty
$$

Akibatnya untuk setiap $k$ barisan $\left\{x_{k}^{(n)}\right\}_{k \geq 1}$ adalah barisan Cauchy di $R$ yang lengkap, artinya untuk setiap $k$ terdapat $x_{k} \in R$ sedemikian hingga

$$
x_{k}^{(n)} \rightarrow x_{k} \quad \text { untuk } n \rightarrow \infty
$$

Selanjutnya dibentuk $x=\left\{x_{k}\right\}$. Akan dibuktikan

i. $\left\|x^{(n)}-x\right\| \rightarrow 0$, untuk $n \rightarrow \infty$

$$
\begin{aligned}
\left\|x^{(n)}-x\right\| & =\left|x_{1}^{(n)}-x_{1}\right|+\left\|\Delta x^{(n)}-\Delta x\right\|_{\ell_{\varphi}} \\
& =\left|x_{1}^{(n)}-x_{1}\right|+\left\|\left(x_{k}^{(n)}-x_{k-1}^{(n)}\right)-\left(x_{k}-x_{k-1}\right)\right\|_{\ell_{\varphi}} \\
& \leq\left|x_{1}^{(n)}-x_{1}\right|+\left\|x_{k}^{(n)}-x_{k}\right\|_{\ell_{\varphi}}+\left\|x_{k-1}^{(n)}-x_{k-1}\right\|_{\ell_{\varphi}}
\end{aligned}
$$

Sehingga untuk $n \rightarrow \infty$ diperoleh
a. $\left|x_{1}^{(n)}-x\right| \rightarrow 0$
b. $\left\|x_{k}^{(n)}-x_{k}\right\| \rightarrow 0$, untuk $n \rightarrow \infty$

Dengan demikian $\left\|x^{(n)}-x\right\| \rightarrow 0$, untuk $n \rightarrow \infty$.

ii. Akan ditunjukkan $x \in \ell_{\varphi}(\Delta)$ berarti menunjukkan bahwa $\Delta x \in \ell_{\varphi}$. Terdapat bilangan bulat positip $N$ sehingga sedemikian hingga

$$
\sum_{k=1}^{\infty} \varphi\left(\Delta x_{N}-\Delta x\right)<1<\infty
$$

sehingga $\Delta x_{N}-\Delta x \in \ell_{\varphi}$ dengan $\ell_{\varphi}$ adalah linier, maka $\Delta x \in \ell_{\varphi}$.

Dengan demikian i dan ii dipenuhi. Jadi $\ell_{\varphi}(\Delta)$ lengkap.

Berikutnya akan ditunjukkan bahwa $\ell_{\varphi}(\Delta)$ mempunyai sifat $A K$ yaitu $\| x^{N}$ $x \|_{\ell_{\varphi}} \rightarrow 0$ untuk $N \rightarrow \infty$. Untuk menunjukkan ini, diberikan

$$
\rho\left(\frac{\Delta\left(x^{N}-x\right)}{\varepsilon}\right)=\sum_{k=N+1}^{\infty} \varphi\left(\frac{x_{k}-x_{k-1}}{\varepsilon}\right)=\sum_{k=N+1}^{\infty} \varphi\left(\frac{\Delta x}{\varepsilon}\right)
$$

Karena $\Delta x \in \ell_{\varphi}(\Delta)$, maka terdapat bilangan bulat $P$, sehingga $\sum_{k=N+1}^{\infty} \varphi\left(\frac{\Delta x}{\varepsilon} \leq \varepsilon\right)$, untuk setiap $N \geq P$. Dengan demikian $\rho\left(\frac{\Delta\left(x^{N}-x\right)}{\varepsilon}\right) \geq$ $\varepsilon$ untuk setiap $N \geq P$. 
Oleh karena itu $\left\|x^{N}-x\right\| \leq \varepsilon$ untuk $N \geq P$. Dengan kata lain $\left\|x^{N}-x\right\| \rightarrow$ 0 untuk $N \rightarrow \infty$. Dari penjabaran di atas bahwa ruang barisan Orlicz selisih merupakan ruang Frechet, sehingga mempunyai $G H P$ dan mempunyai sifat $A K$ yaitu $\left\|x^{N}-x\right\|_{\ell_{\varphi}} \rightarrow 0$ untuk $N \rightarrow \infty$, dengan $x^{N}=\left\{x_{1}, x_{2}, \cdots, x_{N}, 0, \cdots\right\}$ dari setiap barisan $x=\left(x_{k}\right) \in \ell_{\varphi}(\Delta)$.

Maka ruang barisan Orlicz selisih memenuhi sifat $\left\|x^{N}\right\| \leq\|x\|$, untuk setiap $x \in \ell_{\varphi}(\Delta)$.

\section{Fungsional Aditif dan Kontinu pada Ruang Barisan Orlicz Selisih}

Sekarang akan dijabarkan tentang Fungsional aditif dan kontinu pada ruang barisan orlicz selisih. Sebelumnya akan dibahas teorema-teorema yang akan digunakan untuk mengkonstruksi fungsional aditif dan kontinu pada ruang barisan Orlicz selisih sebagai berikut.

Teorema 4.1 Diberikan $X$ ruang barisan yang mempunyai sifat AK. Jika $f$ adalah fungsional aditif dan kontinu pada $X$, maka $f(x)=\sum_{k=1}^{\infty} g\left(k, x_{k}\right)$ ada, untuk setiap $x=\left\{x_{k}\right\} \in X$. Dengan $g(k, 0)=0$ dan $g(k,$.$) kontinu, untuk setiap k \in N$

Bukti. Diberikan $e^{k}$ yaitu barisan dengan elemen ke- $k$ sama dengan 1 dan 0 untuk yang lain. Karena $X$ mempunyai sifat $A K$, maka untuk setiap dan $X$ memuat semua barisan berhingga, $\left\|x^{N}\right\| \leq\|x\| \rightarrow 0$, untuk $N \rightarrow \infty$. Oleh karena $f$ aditif dan kontinu maka

$$
\left\|f\left(x^{N}-x\right)\right\| \rightarrow 0, \quad \text { untuk } \quad N \rightarrow \infty
$$

atau

$$
\left\|f\left(x^{N}\right)-f(x)\right\| \rightarrow 0, \quad \text { untuk } N \rightarrow \infty
$$


atau

$$
\begin{aligned}
f(x) & =\lim _{N \rightarrow \infty} f\left(x^{N}\right) \\
& =\lim _{N \rightarrow \infty} f\left(\sum_{k=1}^{N} x_{k} e^{k}\right) \\
& =\lim _{N \rightarrow \infty} \sum_{k=1}^{N} f\left(x_{k} e^{k}\right) \\
& =\sum_{k=1}^{\infty} f\left(x_{k} e^{k}\right) \\
& =\sum_{k=1}^{\infty} g\left(k, x_{k}\right)
\end{aligned}
$$

dengan $g(k, t)=f\left(t e^{k}\right)$ dan $g(k, t)$ adalah fungsi kontinu untuk setiap $k \in N$.

Teorema 4.2 Diberikan X ruang barisan yang mempunyai GHP yang memuat semua barisan berhingga dan $\left\|x^{N}\right\| \leq\|x\|$, dan diberikan $f$ adalah fungsional pada $X$, jika $g(k, 0)=0$ dan $g(k,$.$) kontinu untuk setiap k \in N$ sehingga

$$
f(x)=\sum_{k=1}^{\infty} g\left(k, x_{k}\right) \quad a d a, \forall x=\left\{x_{k}\right\} \in X
$$

maka $f$ adalah fungsional aditif dan kontinu.

Bukti. Akan dibuktikan $f$ adalah kontinu. Sekarang andaikan $f$ tidak kontinu di $x \in X$, maka terdapat barisan $\{y(i)\} \in X$ sedemikian hingga $\left\|y^{(i)}-x\right\| \rightarrow 0$ untuk $i \rightarrow \infty$.

Tetapi $\left|\sum_{k=1}^{\infty} g\left(k, y^{(i)}\right)-\sum_{k=1}^{\infty} g\left(k, x_{k}\right)\right|>\varepsilon$ untuk semua $i$.

Akan disusun dua barisan dari bulat positip sebagai berikut : Ambil $n(0)=0 ; m(1)=1$ dan dipilih $n(1)$ sedemikian hingga

$$
\left|\sum_{k=n(0)+1}^{n(1)} g\left(k, y_{k}^{(m(1))}\right)-\sum_{k=1}^{n(1)} g\left(k, x_{k}\right)\right|>\varepsilon
$$

karena $g(k,$.$) adalah kontinu untuk k=1,2, \cdots, n(1)$, maka terdapat $m(2)>$ $m(1)$ sedemikian hingga

$$
\left|\sum_{k=1}^{n(1)} g\left(k, y_{k}^{(m(2))}\right)-\sum_{k=1}^{n(1)} g\left(k, x_{k}\right)\right| \leq \frac{\varepsilon}{2}
$$


selanjutnya terdapat $n(2)>n(1)$ sedemikian hingga

$$
\left|\sum_{k=1}^{n(2)} g\left(k, y_{k}^{(m(2))}\right)-\sum_{k=1}^{n(2)} g\left(k, x_{k}\right)\right|>\varepsilon
$$

Dari kedua pertidaksamaan diatas didapat

$$
\left|\sum_{k=n(1)+1}^{n(2)} g\left(k, y_{k}^{(m(2))}\right)-\sum_{k=n(1)+1}^{n(2)} g\left(k, x_{k}\right)\right|>\frac{\varepsilon}{2}
$$

Secara umum dapat diperoleh barisan naik dari dua bulat positip $\{n(i)\}$ dan $\{m(i)\}$ sedemikian hingga

$$
\left|\sum_{k=n(i-1)+1}^{n(2)} g\left(k, y_{k}^{(m(i))}\right)-\sum_{k=n(i-1)+1}^{n(i)} g\left(k, x_{k}\right)\right|>\frac{\varepsilon}{2}
$$

, untuk setiap $i=1,2,3, \cdots$

Sekarang didefinisikan barisan blok $\left\{z^{i}\right\}$ di $X$ dengan

$$
z^{i}=\left\{0, \cdots, 0, y_{n(i-1)+1}^{(m(i))}-x_{n(i-1)+1}, \cdots, y_{n(i)}^{(m(i))}-x_{n(i)}, 0, \cdots\right\}
$$

untuk $i=1,2,3, \cdots$

Mengingat asumsi bahwa $\left\|x^{N}\right\| \leq\|x\|$ diperoleh

$$
\left\|z^{i}\right\| \leq 2\left\|y^{(m(i))}-x\right\| \rightarrow 0, \quad \text { untuk } i \rightarrow \infty
$$

karena $X$ mempunyai $G H P$, maka terdapat sub barisan $\{i(k)\}$ sedemikian hingga

$$
z=\sum_{k=1}^{\infty} x^{i(k)} \in X
$$

Oleh karena itu $\sum_{k=1}^{\infty} g\left(k, z_{k}+x_{k}\right)-\sum_{k=1}^{\infty} g\left(k, x_{k}\right)$ adalah konvergen.

Yang kontradiksi dengan pengandaian diatas. Dengan demikian $f$ adalah kontinu di $x$ untuk setiap $x \in X$

Akibat dari Teorema 4.1 dan Teorema 4.2 serta memperhatikan sifat-sifat dari ruang barisan Orlicz selisih yang telah dijabarkan di atas, maka dapat dikontruksi fungsional aditif dan kontinu pada ruang barisan Orlicz selisih yang diberikan dalam teorema berikut.

Teorema 4.3 Fungsional $f: \ell_{\varphi}(\Delta) \rightarrow R$ aditif dan kontinu jika dan hanya jika $f(x)=\sum_{k=1}^{\infty} g\left(k, x_{k}\right)$ ada, untuk setiap $x=\left\{x_{k}\right\} \in \ell_{\varphi}(\Delta)$ dengan $g(k, 0)=0$ dan $g(k,$.$) kontinu untuk setiap k \in N$. 
Bukti. Karena ruang barisan Orlicz selisih merupakan ruang Frechet, maka mempunyai $G H P$ serta mempunyai sifat $A K$ dan juga memenuhi sifat $\left\|x^{N}\right\| \leq$ $\|x\|$, untuk setiap $x \in \ell_{\varphi}(\Delta)$ serta akibat dari Teorema 4.1 dan Teorema 4.2.

\section{Pustaka}

[1] Chew, T. S., 1985, Orthogonally Additive Functionals, PhD. Disertation, national University of Singapore.

[2] Colak, R and Mikail ET, 1997, On some generalized difference sequence spaces and related matrix transformations, Hokkaido mathematical Journal, Vol 26 (p.483 - 492) Japan.

[3] Lee, P.Y, 1993, Sequence Space and the Gliding Hump Property, SEA Bull, Math. 17, 65-72

[4] Sadjidon dan Sri Daru, 2002, Ruang Barisan Orlicz, Makalah Thesis UGM. 